\title{
The Cultural Landscape of the "Grecanic Area" and the Recovery of the Genius Loci of its Historical Centres
}

\author{
Daniele Campolo ${ }^{1, a}$ \\ ${ }^{1}$ Mediterranea University of Reggio Calabria - P.A.U. - Department of Heritage, Architecture, Urban \\ Planning, via Salita Melissari - 89124, Reggio di Calabria, Italy \\ adaniele.campolo@unirc.it
}

Keywords: Intangible Heritage, Area Grecanica, Cultural Landscape, Genius Loci, Development, Historical Centres.

\begin{abstract}
The "Grecanic Area" in the province of Reggio Calabria is a region with an enormous heritage of great cultural value, surrounded by a still intact natural heritage, but now, despite some attempts to nominate the "Ellenofona Island" (ancient Greek - speaking area) in the List of the immense Cultural Heritage of mankind, this territory is not still considered despite of its value: it would be sufficient to focus mainly on the values of the great cultural heritage and the natural heritage and on the "genius loci" of the historic centres of the "Grecanic Area".

The aim of this paper is to highlight how the protection and enhancement of these assets could contrast phenomena of emigration and depopulation of the inland areas and the socio-economic disintegration in favour of a re-appropriation of the cultural identity of an area that has remained virtually unchanged for many centuries.

Starting from the new discovery of the "genius loci" of the ancient historic villages in the Grecanic Area, the conservation and the enhancement of natural and great heritage allows to pursue a sustainable development, using local resources as a "visiting card" of the territory, the natural landscape and the wildlife heritage.
\end{abstract}

\section{Introduction}

For many years, an action of sedimentation of knowledge and skills, in relation to the Grecanic culture was carried on thanks to the action of the P.A.U. (Urban and Architectural Heritage) Department of the Mediterranea University of Reggio Calabria, which has promoted and supported the local culture. The main aims of the project are to safeguard the huge great heritage which is running the risk of disappearing, consisting in the Greek language, traditions (art, music, dance, rituals, crafts and knowledge, etc.) and the tangible heritage consisting in vernacular architecture and to create opportunities for the development of the territory, especially in the internal areas of the Province of Reggio Calabria. The development strategy is focused on sustainable tourism that could lead to a revitalization effect, boosting economic activities related to the historical roots of the Magna Graecia, promoting new opportunities for development and the strong impact on the phenomenon of migration. Migration, in particular in recent decades, has led to the abandonment and often the loss of important features of the historical memory of this territory.

\section{The cultural landscape of the Grecanic area}

The particular importance of the Grecanic Area as an immense heritage is the cultural history of its colonization: Calabria Region, in the past centuries, has been a land of refuge for groups of different culture and religion from various Mediterranean areas. Today in this area it is still possible to identify three major ethnic minority languages related to historical events dating back to past times: the Ancient Greek minority language in the province of Reggio Calabria, the Occitan or Waldensians culture and the Albanians or Arbëreshë culture.

The Grecanic Area consists of those populations that historically have been identified as the last living witnesses of the Hellenic diaspora of settlers that have colonized the coast of Calabria in 
successive waves, in a "plausible juxtaposition, in different times, between recent Greek colonies and the oldest ones" [1].

The Ellenofona Island, generally identified with the "core zone" of the Grecanic Area, is located in the mountains in the province of Reggio Calabria, between the Tyrrhenian and the Ionian Sea, in the South Ionic Slopes of Aspromonte. The area is part of the National Park of Aspromonte, and it is characterized by an uncontaminated nature formed by characteristic rivers, waterfalls, breathtaking views, charming historic towns, forming a "cultural landscape"; its ancient culture is also a particular attraction: the area is a linguistic island where people speak a language which is similar to the ancient Greek language, and the traditions together with the ancient knowledge is a treasure of immense cultural value.

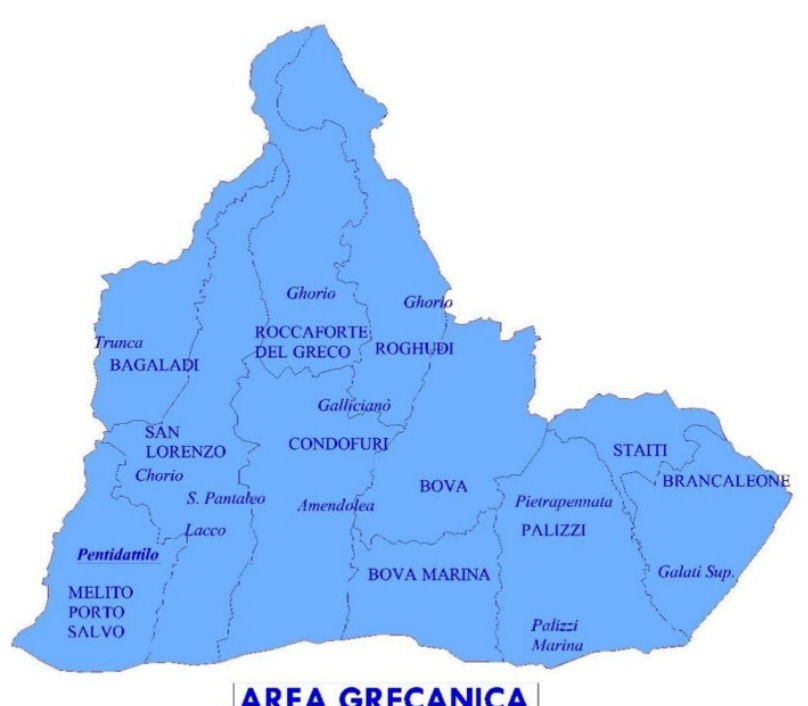

AREA GRECANICA

Fig.1: The Grecanic Area in the province of Reggio Calabria
For centuries this area has been isolated in a cultural and geographic way because of the precariousness of the infrastructures. From the Byzantine period, in fact, the towns moved from the coasts to the mountains for defensive reasons and for healthy reasons, because of the marshes along the coasts. On one hand this situation produced a closed and self-sufficient economy, and a "fragmented" country, where towns were linked together by footpaths and muleteer, but with no real infrastructures to connect with the main coast towns and the provincial capital; and on the other hand it allowed to preserve intact the Hellenistic culture and the Greek-Calabrian language.

The Ellenofona Island coincides with the municipalities of Bova (Chora tu Vùa - Vùa), Bova Marina (Fundaca - Jalò tu Vùa), Condofuri (Kondochori), Roccaforte del Greco (Vuni) and Roghudi (Richùdi), but the real cultural boundaries of the Greek minority in Calabria are extended because the neighboring municipalities keep alive the cultural traditions related to the Greek world (Fig. 1).

In the nineteenth century the Calabria Ellenofona had probably spread throughout the area of Southern Ionian Aspromonte. Between the nineteenth and twentieth century, the spoken language disappears from Pentidattilo, Palizzi, Staiti, Brancaleone and Africo. The enormous social and economic transformations of the twentieth century, the belief that the language of the Hellenistic age was a symptom of backwardness and underdevelopment, a series of landslides and floods in the Grecanic centres, the diffusion of television and the construction of the first driveways in the second half of the twentieth century, contributed to the loss of the Greek language in many centers.

The Greek language of Calabria (or Grecanic) is today spoken by a few people, mostly elderly, with a high risk of loss of this idiom, despite numerous promotional actions carried out primarily by some Grecanic cultural associations.

This territory for its characteristics could be defined as "Cultural Landscape". Cultural landscapes have been defined by the World Heritage Committee as "cultural properties ... represent[ing] the combined works of nature and man".

In the category of "organically evolved landscape" which may be a "relict (or fossil) landscape" or a "continuing landscape"[2].

The territories concerned by the cultural landscapes of Grecanic Area minorities are generally regarded as relict-economic systems. They are located at the edge of developed agricultural areas and generally near the inland areas and mountain foothills. 
In less developed areas, such as the district of Reggio Calabria, the cultural landscape has played a vital economic role as the only means of livelihood for the entire territory, providing variety and typical products in addition to the protection of biodiversity and the sustainable use of all its resources.

These territories are formed hierarchically by different ecosystems, deeply influenced by various factors such as the geological composition of the soil, the microclimate, the presence of the "fiumare" (characteristic Calabrian rivers), the geographical setting difficulties for agriculture and the use of terracing techniques to overcome the lack of large flat areas. The different combinations of these micro-ecosystems creates a complex landscape that can be observed at different scales and it is determined by human management of the various natural resources.

Basically these cultural landscapes can be expressed by three basic components: a natural component, a cultural component and an economic component.

The natural component is expressed by the various habitats which include particularly valuable endemic species; the cultural component is linked to the different use of human resources and the cultural knowledge: ethical and religious beliefs, related to the use of land, language, crafts, food and drink, etc.; the economic component is related to the use, in different seasons, of the natural resources of the area at a local level and it is connected to the capacity to attract tourists.

The territories of the three linguistic minorities are also united by the following requirements, which are recognized, in the academic, as prerequisites to determine the existence of a "traditional cultural landscape":

a) isolation (in geographic, economic, infrastructural, political, cultural terms);

b) the geographical setting difficulty for agriculture with scarcity of resources;

c) inhabitants ethnically and/or socially different from the national mainstream;

Actually isolation was also found to be the reason for the latter two preconditions for traditional cultural landscapes [3].

Despite the technological innovations and the "uncontrolled building" in recent decades, most of these areas still retain much of their traditional cultural landscapes because agriculture is still practiced with typical techniques related to traditional knowledge.

The use of traditional farming in these areas is based mainly on agricultural production in the "terrace-gardens" derived from the mountain slopes or in the proximity of the "fiumare", with the cultivation of fruit trees and animal husbandry.

The rough climatic and soil conditions have forced local communities to adapt to their territory, transforming the landscape; for this reason the local communities were able to use the whole range of natural resources available in the area, in a integrate way.

All the traditional elements of the agricultural landscape: terraces, dry-stone walls, trails, buildings, irrigation canals are built with local materials and stones taken from the beds of the "fiumare".

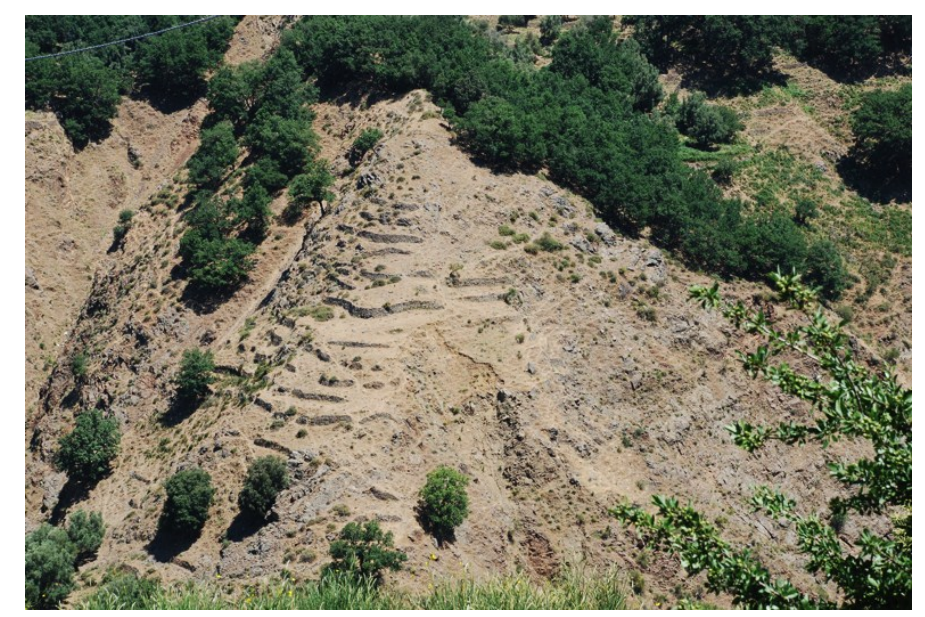

Fig. 2: The "terrace-gardens" system in Roghudi
Agriculture is still carried out on a subsistence level, practiced by many people who grow grapes, olives and citrus fruits ( the cultivation of the bergamot is widespread in the Grecanic Area) which allows a small profit; this kind of agriculture still remains the only form of employment for most of the population, although it does not generate an official income.

This landscape of particular interest for its environment, presents a condition of absolute uniqueness and exceptionality in relation to the persistence of the Grecanic language, a strong element of cultural identity. This 
language has been preserved up to now, in spite of the contamination, with the presence of a culture of ancient Greek origin and it has led to the formation of strongly characterized territories

In particular, "fiumare" play a key role in the Grecanic landscape: they are, at the same time, a means of communication to the coast, a source of water supply for the irrigation of the fields, a reserve of building materials, a level place to grow, but also an ecosystem to protect and to enhance; the "terrace-gardens" system derived from the mountain slopes or in the nearby of the "fiumare", that makes up for the lack of large and flat areas and allows sustainable management and control of the territory, preventing landslides and instability of slopes (Fig. 2).

The natural component of this area is characterized by the contrast between the mountain, which reaches 2.000 meters above the sea level, and the sea that surrounds it, creating, for the exceptional microclimate conditions and the geological characteristics of the soil, the ideal habitat for some endemic species, unique in the world, such as the bergamot, the annona, or plants typical of the Mediterranean Area: jasmine, olive, citrus and Mediterranean Scrub.

\section{The "genius loci" of the cultural landscape in the Grecanic Area}

Another characteristic element of the "Grecanic Landscape" consists in the historical centers built on the top of the mountain slopes or near the river-beds: an architectural heritage characterized by authenticity and uniqueness criteria for both construction technologies and for the use of traditional materials.

In the past centuries, before constructing a building or any sign on the ground, people observed and studied the territory carefully: they chose the place with extreme attention in relation to the surrounding nature, the level curve, the existing buildings, to resources of the area, keeping in mind the function that the space was built to perform.

The villages were built, not in a random way, but they were built in a particular area which was very often chosen on the basis of a sacred event that made the place privileged.

Sites were chosen not only for defensive and strategic reasons, but also because of the presence of waterways, water supply, or the proximity to the sea.

Despite this attention the Grecanic territory, over the centuries, has been plagued by destructive events (earthquakes, floods, landslides) that prevented a human "continuous" settlement and an intensive agricultural purpose. This on the one hand has allowed the preservation of natural and environmental heritage, on the other hand has caused the disappearance of the intangible heritage.

An intangible culture is based on the material heritage that is the explanation, and the hallmark: it is therefore of prime importance that we select and highlight all those materials signs like tools, artifacts, cultural spaces that are recognized by the people and local communities as integral and complementary part of their intangible heritage.

But the protection and enhancement of these areas cannot be separated from the recognition of the "genius loci", understood as the study of the interaction between the environment, the place and the identity of the people who historically inhabited a specific area, with the set of socio-cultural, architectural, linguistic features.

"The Genius Loci, the spirit of the place, is what survives the continuous changes of the structure and function and it confers an indelible character to cities and landscapes, making different architectural phenomena, in the forms in time, parts of a single and recognizable experience.'[4]

These considerations have been at the center of meeting in the historic city of Quebec in Canada from 29 September to 4 October 2008, on the occasion of the 16th General Assembly of ICOMOS (International Council on Monuments and Sites). The participants adopted the Declaration of principles and recommendations to preserve "the spirit of place" through the safeguarding of tangible and intangible heritage, which is regarded as an innovative and efficient manner to ensure sustainable and social development in the world.

"The Québec Declaration has provided an opportunity to further explore the relationship between tangible and intangible heritage, and the internal social and cultural mechanisms of the spirit of place. 
Spirit of place is defined as the tangible (buildings, sites, landscapes, routes, objects) and the intangible elements (memories, narratives, written documents, rituals, festivals, traditional knowledge, values, textures, colors, odors, etc.), that is to say the physical and the spiritual elements that give meaning, value, emotion and mystery to place." [5]

In particular, the principles 8 and 9 of the Declaration of Quebec put the focus on local communities that have the primary task of the transmission of the Spirit of the place in their territory: "Recognizing that spirit of place is transmitted essentially by people, and that transmission is an important part of its conservation, we declare that it is through interactive communication and the participation of the concerned communities that the spirit of place is most efficiently safeguarded, used and enhanced. Communication is the best tool for keeping the spirit of place alive." [5]

\section{Conclusions}

The strategic role of local communities is even more relevant in the Grecanic territory where still many population groups do not understand the importance and the economic, social and cultural potentialities of this heritage.

Increased knowledge and dissemination of heritage assets (both tangible and intangible) can create a stronger sense of identity among the inhabitants of the area, it can increase the social capital and it can stimulate the collective consciousness of both private and public administrations in the recovery and enhancement of material and cultural goods.

The awareness of residents of the minority language culture is the primary element for the implementation and the development of the territory. The effectiveness of this strategy is in the ability of local community to assume development programs as a shared goal of community.

For many years the local governments have realized the importance of the enhancement of local resources through the common planning as the result of political consultation and cooperation between actors at various level.

The preservation and enhancement of the intangible heritage of this area also allows us to pursue a sustainable development; to generate a revitalization effect on the territory; to create an interaction between the characteristics of the local culture and the socio-economic structures of the area, through a revival of activities related to the cultural and historical roots of the Ellenofona Island; to reverse the trend with the repopulation of inland areas; to achieve development objectives, coherent with the policies of the Region of Calabria that aims to a cultural tourism.

The territory should not be conceived as a static object but as the result of a constant evolution that shows the different periods of life and cultures that inhabited it; it is therefore important not to eliminate the traces and memories of the past, but to enhance the historical, architectural and naturalistic characters.

The process of growth and development should always be in harmony with its surroundings: a prerequisite for the development of a territory is the existence of a well-defined identity, a compact and cohesive local community, a particular attention to the cultural traditions [6].

The creation of goods and services is linked to a specific identity of the place, where knowledge is part of a system of information: this implies, therefore, the presence of a local cultural system, and the presence of an adequate and solid socio-cultural and environmental structure.

This structure will be the basis where to start processes of development and support of local cultural, to promote the development of local economy, to improve the livability condition of the territory.

The main task will be to decline the culture, not merely as a product to sell, but as a product to improve and to promote, enhancing the existing resources and developing the processes of innovation that are the basis of the knowledge, of economy and of cultural production. 


\section{References}

[1] D. Comparetti: Saggi dei dialetti greci dell'Italia Meridionale, Fratelli Nistri Editore, Pisa (1866)

[2] UNESCO: Operational Guidelines for the Implementation of the World Heritage Convention. UNESCO World Heritage Centre. Paris. (2012) p. 14

[3] D. Campolo: The Cultural Landscape of Linguistic Minorities in the Calabrian Region: Cultural Premises for Intervention and a Study Case in the Grecanic Area, In: SOCIETY, INTEGRATION, EDUCATION Utopias and dystopias in landscape and cultural mosaic. Visions Values Vulnerability Proceedings of the International Scientifical Conference June 27th - 28th, 2013 Volume III . SABIEDRIBA, INTEGRACIJA, IZGLITIBA, vol. III, pp. 39-48, ISSN: 1691-5887, Udine, 27-28 Giugno 2013

[4] C. Norberg-Shulz: Genius Loci. Paesaggio, Ambiente, Architettura, Electa, Milano (1979)

[5] Dichiarazione di Québec sulla conservazione dello Spirito del Luogo, adottato in Québec, Canada, 4 ottobre 2008

[6] F. Calabrò, L. Della Spina: The cultural and environmental resources for sustainable development of rural areas in economically disadvantaged contexts. Economic-appraisals issues of a model of management for the valorisation of public assets. In 3rd International Conference on Energy, Environment and Sustainable Development (ICEESD 2013). Advanced Materials Research Vols. $869-870$ (2014) pp 43-48 (C) (2014) Trans Tech Publications, Switzerland doi:10.4028/www.scientific.net/AMR.869-870.43, (2014) 